\title{
Bandgap and band edge positions in compositionally graded $\mathrm{ZnCdO}$
}

\author{
I. J. T. Jensen, ${ }^{1, a)}$ K. M. Johansen, ${ }^{2}$ W. Zhan, ${ }^{2}$ V. Venkatachalapathy, ${ }^{2}$ L. Brillson, ${ }^{3}$ \\ A. Yu. Kuznetsov, ${ }^{2}$ and $\varnothing$. Prytz $^{2}$ \\ ${ }^{1}$ SINTEF Materials Physics, P/O Box 124 Blindern, 0314 Oslo, Norway \\ ${ }^{2}$ Department of Physics, University of Oslo, P/O Box 1048 Blindern, 0316 Oslo, Norway \\ ${ }^{3}$ Department of Electrical and Computer Engineering, Ohio State University, Columbus, Ohio 43210, USA; \\ Department of Physics, Ohio State University, Columbus, Ohio 43210, USA; and Center for Materials \\ Research, Ohio State University, Columbus, Ohio 43210, USA
}

(Received 18 April 2018; accepted 8 June 2018; published online 3 July 2018)

\begin{abstract}
Introducing $\mathrm{Cd}$ into $\mathrm{ZnO}$ allows for bandgap engineering, potentially with particularly interesting properties to observe in compositionally graded samples. In this work, compositionally graded $\mathrm{Zn}_{1-x} \mathrm{Cd}_{x} \mathrm{O}$ samples with $0 \leq x<0.16$ were made using metal organic vapour phase epitaxy. The chemical composition was studied using scanning transmission electron microscopy, while the band structure of the samples was investigated using a combination of cathodoluminescence spectroscopy and X-ray photoelectron spectroscopy (XPS). It is found that the reduction of the bandgap in our samples is caused by changes in the conduction band. The position of the Fermi level relative to the vacuum level, i.e., the workfunction, was also found to change upon addition of $\mathrm{Cd}$, giving an apparent shift in the valence band when evaluated from the XPS valence spectra. Published by AIP Publishing. https://doi.org/10.1063/1.5036710
\end{abstract}

\section{INTRODUCTION}

Group-II oxides represent direct wide-bandgap semiconductors that share many attractive features with group-III nitrides, making them promising for electronic applications. The unique combination of high exciton binding energy and the broad bandgap tunability range from $4.8 \mathrm{eV}$ to $1.8 \mathrm{eV}$ in wurtzite $\mathrm{MgO}-\mathrm{ZnO}-\mathrm{CdO}$ compounds can benefit a number of modern device applications, including recently demonstrated solar-blind photodetectors, thin-film transistors (TFTs) for smart displays, tandem solar cells, as well as in yet to be established approaches in realizing light emitting diodes (LEDs), resistive switching (RS) devices, etc. ${ }^{1-7}$ These developments, however, are hampered by several unresolved issues, notably by unreliable p-type doping, phase separation in ternary alloys, etc. Indeed, $\mathrm{ZnO}$ exhibits native n-type conductivity, and numerous attempts to convert it to p-type by controlling acceptor-type intrinsic defects (zinc vacancy $\mathrm{V}_{\mathrm{Zn}}$ and oxygen interstitials $\mathrm{O}_{i}$ ) and by doping with relevant acceptor impurities (N, Na, P, Ag, etc.) have had very limited success so far. ${ }^{8}$

A fundamentally new way to create conductivity in noncentrosymmetric crystal structures, called polarization-induced doping (PID), was proposed by Jena et al. ${ }^{9}$ and later demonstrated in III-nitrides by grading the composition of AlGaN along its c-axis, the direction along which the polarization dipoles lie in wurtzite. ${ }^{10}$ In uniaxial crystals, spontaneous polarization arises due to the ionic character of the bonds between atoms and their asymmetric positions within the structure. For noncentrosymmetric crystals with a composition varying along the direction of the dipoles, a fixed (bound) polarization charge builds up because the neighbouring dipoles in the graded alloy are not of the same magnitude anymore and thus no longer cancel each other. To maintain the overall

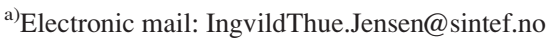

charge neutrality, the bound polarization charge accumulated in the crystal must be compensated by mobile (free) charge carriers, which can be provided from elsewhere, e.g., the surface states. ${ }^{11}$ The outcome of such charge rearrangements is ntype (or p-type) conductivity with bound polarization charge acting as a local donor (or an acceptor) with zero activation energy, as well as higher carrier mobilities due to removal of ionized impurity scattering. Compositionally graded $\mathrm{ZnCdO}$ and $\mathrm{ZnMgO}$ have raised interest as possible candidates for PID. By taking advantage of the large polarization charges typical for group II oxides and controlling the composition gradient during synthesis, the resultant electric fields can be arranged in a way to create spatially separated electrons or holes without introducing dopants, potentially resolving the doping asymmetry inherent to this family of wide-bandgap semiconductors. Moreover, compositionally graded films are used as buffer layers to synthesize, e.g., $\mathrm{ZnMgO}$ exhibiting an ultimately high $\mathrm{Mg}$ content. ${ }^{3}$ Altogether, this makes investigations of such compositionally graded samples of high interest.

Introducing $\mathrm{Cd}$ into $\mathrm{ZnO}$ reduces the bandgap $\left(\mathrm{E}_{\mathrm{g}}\right)$, but no general framework exists for predicting the position of the band edges of $\mathrm{Zn}_{1-x} \mathrm{Cd}_{x} \mathrm{O}$ relative to the Fermi level $\left(\mathrm{E}_{\mathrm{F}}\right)$. The $\mathrm{E}_{\mathrm{g}}$ reduction can be accommodated by changes either in the valence band, the conduction band, or both. Furthermore, the influence of intrinsic defects on the band structure may change as the bandgap changes, affecting the position of the Fermi level relative to the band edges, e.g., making the semiconducting material more or less $\mathrm{p}$ - or n-type. When materials are combined to form heterojunctions, which is central to advances in device development, the Fermi levels of the different materials will line up. The core, valence, and conduction bands may thus have to bend to make up for band structure mismatches between the two materials. It is largely the shape of the band bending across the interface, e.g., formation of barriers, which controls the device functions. This 
shape relies on the difference in workfunctions and the alignment of the band edges. To some extent, models for predicting the shape of band bending across interfaces exist for certain material classes, but a general understanding is still lacking. ${ }^{12-14}$ Particularly for new alloyed materials such as $\mathrm{Zn}_{1-x} \mathrm{Cd}_{x} \mathrm{O}$, characterization of the band structure is important for potential applications.

In a density functional theory (DFT) study of the electrical and optical properties of $\mathrm{Zn}_{1-x} \mathrm{Cd}_{x} \mathrm{O}$ with $x \leq 0.25$, Zhang et $a l .{ }^{15}$ found the bandgap decrease to be caused by changes in the conduction band. An increase in $s$ states was observed upon introduction of $\mathrm{Cd}$, shifting the $\mathrm{Zn} 4 s$ states in the lowest conduction band closer to the $\mathrm{O} 2 p$ states in the highest valence band. To date, only a few X-ray photoelectron spectroscopy (XPS) based studies of band edge positions in $\mathrm{ZnCdO}$ have been reported, with diverging conclusions. According to Chen et al., ${ }^{16}$ who studied molecular beam epitaxy grown samples with composition $\mathrm{Zn}_{0.95} \mathrm{Cd}_{0.05} \mathrm{O}$, both the valence band maximum $\left(\mathrm{E}_{\mathrm{V}}\right)$ and the conduction band minimum $\left(E_{C}\right)$ move relative to the Fermi level, by $+0.17 \mathrm{eV}$ and $-0.30 \mathrm{eV}$, respectively. In a study of calcinated $\mathrm{Zn}_{1-x} \mathrm{Cd}_{x} \mathrm{O}$ samples with $x=0,0.039,0.075$, and 1, Lai et al. also found that both band edges shift but with the same magnitude. ${ }^{17}$ In the work of Detert et al., however, it was concluded that the decrease in the bandgap was due to shifts in $\mathrm{E}_{\mathrm{V}}$ only, for pulsed filtered cathodic arc deposited samples with $x=0$, $0.11,0.29,0.56,0.74$, and $1 .^{18}$

In the present work, we study the composition and bandgap energy $\left(\mathrm{E}_{\mathrm{g}}\right)$ of four compositionally graded $\mathrm{Zn}_{1-x} \mathrm{Cd}_{x} \mathrm{O}$ samples with $0 \leq x<0.16$ using scanning transmission electron microscopy (STEM) and cathodoluminescence spectroscopy (CL), respectively. XPS is used to find the position of $\mathrm{E}_{\mathrm{V}}$ relative to the Fermi level, which is combined with $E_{g}$ from CL to determine the position of $E_{C}$.

\section{METHODS}

Thin film samples of $\mathrm{Zn}_{1-x} \mathrm{Cd}_{x} \mathrm{O}$ with varying $\mathrm{Cd}$ concentrations were prepared by metal organic vapour phase epitaxy (MOVPE) along the $c$ axis of $\alpha-\mathrm{Al}_{2} \mathrm{O}_{3}$ substrates buffered with a $\mathrm{ZnO}$ film. The substrates were cleaned with several solutions, rinsed with deionized water, and then dried with $\mathrm{N}_{2}$ gas before loading into the chamber. Diethyl zinc (DEZn), dimethyl cadmium (DMCd), and tertiary butanol (t-BuOH) were used as the zinc source, cadmium source, and oxidizing agent, respectively. For DEZn and $\mathrm{t}-\mathrm{BuOH}$, the flows were set at 100 and $150 \mathrm{sccm}$, respectively. The temperatures of both DEZn and DMCd bubblers were maintained at $10^{\circ} \mathrm{C}$, while that of $\mathrm{t}-\mathrm{BuOH}$ was kept at $30^{\circ} \mathrm{C}$. The $\mathrm{Cd}$ content in the films was varied by changing the $\mathrm{DMCd}$ flow rate while maintaining the growth temperature at $370^{\circ} \mathrm{C}$, which means increasingly metal-rich (oxygen-poor) conditions for increasing $\mathrm{Cd}$ supply. The samples were labelled according to their maximum $\mathrm{Cd}$ content as measured by energy-dispersive X-ray spectroscopy (EDS) (see details below).

XPS was performed using a Thermo Theta Probe instrument with monochromatic Al $\mathrm{K} \alpha$ radiation $(h \nu=1486.6 \mathrm{eV})$ operated at $15 \mathrm{kV}$ and $15 \mathrm{~mA}$. High resolution spectra were collected at a pass energy of $20 \mathrm{eV}$ and a step size of $0.1 \mathrm{eV}$ for core/Auger peaks and $0.05 \mathrm{eV}$ for the VBM region. See Fig. 1 for a typical XPS survey spectrum and the definition of relevant parameters. An area of about $2 \times 2 \mathrm{~mm}^{2}$ was gently cleaned with an $\mathrm{Ar}^{+}$ion beam of $0.5 \mathrm{kV}$ delivering a current of $100 \mu \mathrm{A}$ for $5 \mathrm{~min}$. In order to ensure good electrical contact between the sample and the XPS instrument, Al contacts with

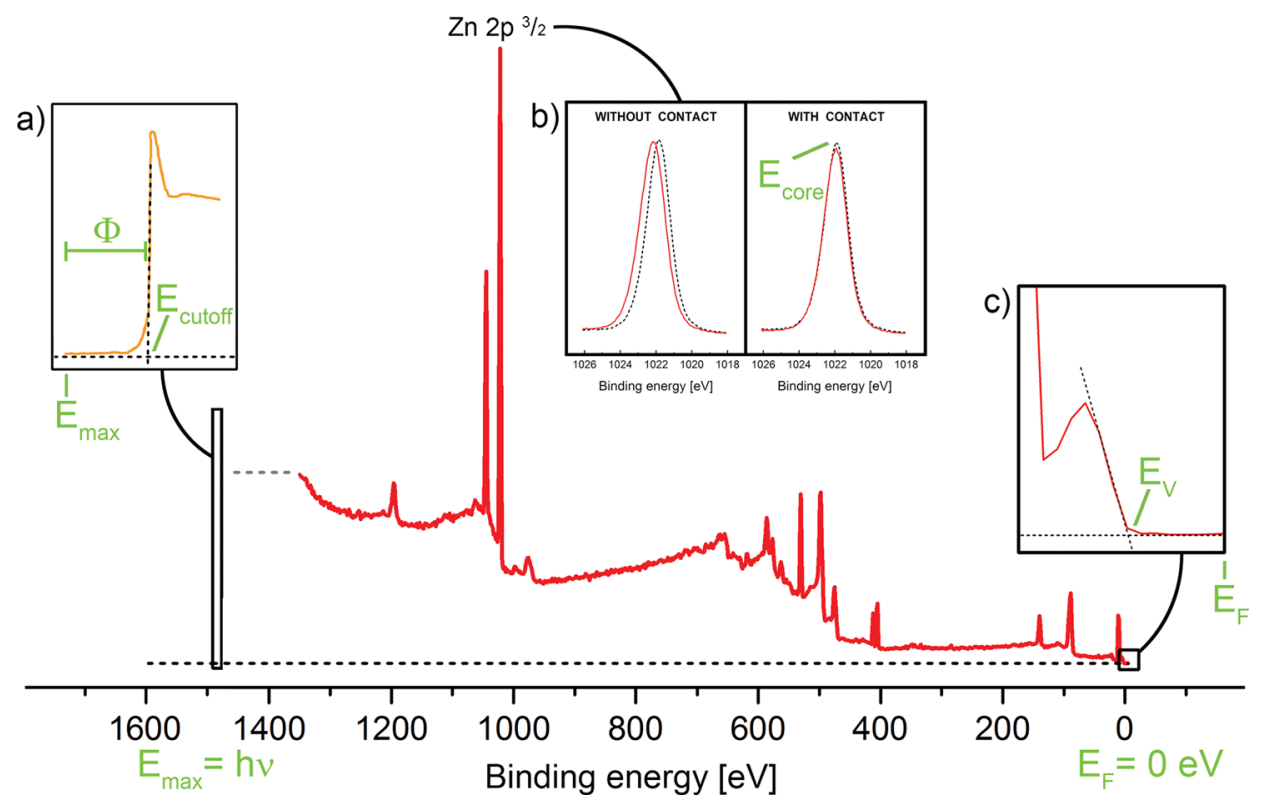

FIG. 1. XPS survey spectrum from the $\mathrm{Cd}_{16}$ sample, with schematic illustrations of relevant parameters. (a) Hypothetical spectrum from the high binding energy (low kinetic energy) region, which is usually not within the detectable range during normal XPS operation. $\mathrm{E}_{\max }$ is the energy of the incoming X-rays; in the present case, it is from an $\mathrm{Al} \mathrm{K} \alpha$ source $(h \nu=1486.6 \mathrm{eV})$. The workfunction $(\Phi)$ is the difference between $\mathrm{E}_{\max }$ and the spectrum cutoff energy ( $\mathrm{E}_{\text {cutoff }}$ ). (b) High resolution spectra from the $\mathrm{Zn} 2 \mathrm{p} 3 / 2$ region: Test of XPS sample charging for $\mathrm{Cd}_{16}$ comparing mounting of the clip directly onto the sample (left) and mounting of the clip onto $\mathrm{Al}$ contact (right), with and without charge compensation (dashed black and solid red line, respectively.) With contact, the peak position ( $\mathrm{E}_{\text {core }}$ ) does not change significantly upon charge compensation. (c) Enhanced view of the valence region, showing the valence band maximum ( $E_{\mathrm{V}}$ ). When the sample is in electrical contact with the instrument, the Fermi level lines up with the binding energy scale $\left(\mathrm{E}_{\mathrm{F}}=0 \mathrm{eV}\right)$. 
a)

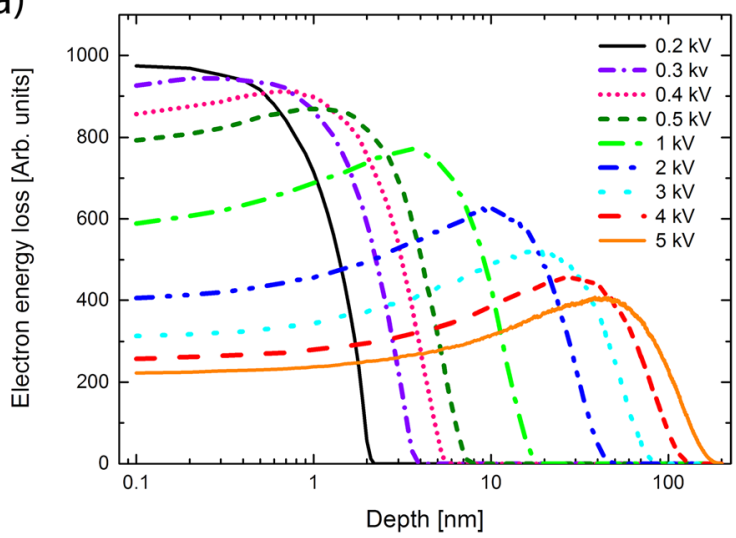

b)

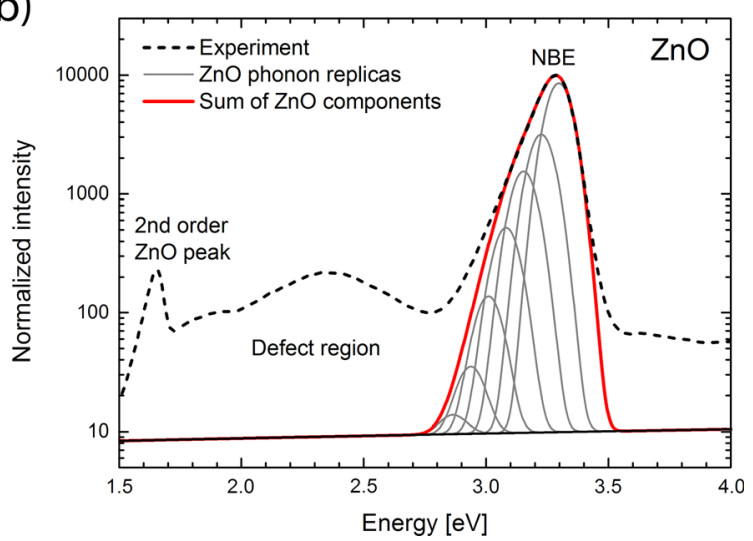

FIG. 2. (a) Calculated electron energy loss in pure $\mathrm{ZnO}$ as a function of the sample depth for different electron beam energies. (b) CL spectrum from pure $\mathrm{ZnO}$, illustrating the fitting of the NBE peak with phonon replicas.

a thickness of $\sim 100 \mathrm{~nm}$ were applied at one corner of each sample. This was done using a Telemark e-beam source in an Angstrom Engineering EvoVac system. The samples were then mounted to the XPS stage by pressing copper clips onto the Al contact area. Figure 1(b) shows an example of the charge compensation test using a low energy electron flood gun. When the sample is mounted with the copper clip onto the $\mathrm{Al}$ contact, no peak shift is observed when the flood gun is used, implying good electrical contact. When the sample is mounted with the copper clip directly onto the sample, however, a clear shift to lower binding energy $\left(E_{B}\right)$ is observed. Thus, the $\mathrm{Al}$ contacts were concluded to improve the electrical contact between the sample and the XPS instrument, and the measurements could be performed without the use of low energy electron charge compensation. XPS spectra were fitted after Shirley ${ }^{19}$ background subtraction, using the CasaXPS software. ${ }^{20}$

Depth resolved CL spectra were obtained in ultra-high vacuum using an electron beam with an angle of $\sim 30^{\circ}$ off the normal incidence, with electron beam energies in the range of $0.2-5 \mathrm{keV}$. The spectra were analyzed by an Oriel monochromator with a slit size of $0.1 \mathrm{~mm}$ and a CCD strip detector. The measurements were performed at room temperature. Each spectrum has been normalized using the near band emission (NBE) peak maximum. Figure 2(a) shows the electron energy loss as a function of the sample depth calculated for pure $\mathrm{ZnO}$ using the CASINO 3.2.0.4 software. ${ }^{21}$ As can be seen, for electron beam energies up to $0.5 \mathrm{kV}$, the penetration depth is in the range of $1-10 \mathrm{~nm}$, which matches the sampling depth of the XPS technique. The CL spectra were fitted using the CasaXPS software. ${ }^{20}$ The bandgap information was extracted from the NBE peaks, which were fitted with a series of phonon replicas with $72 \mathrm{meV}$ spacing. ${ }^{22}$ The $\mathrm{CL}$ spectrum from the pure $\mathrm{ZnO}$ sample was used as a starting point for determining the shape of the NBE peaks in the $\mathrm{Zn}_{1-x} \mathrm{Cd}_{x} \mathrm{O}$ samples. Figure 2(b) shows an example of a CL spectrum with a fitted NBE peak.

For STEM studies, samples were prepared by mechanical cutting, grinding/polishing, and ion beam thinning. The compositions were studied by EDS with a probe-corrected FEI Titan 60-300 instrument, which was operated in the STEM mode at $300 \mathrm{kV}$. In this mode, a spatial resolution of $0.8 \AA$ can be achieved for probe-corrected STEM imaging. The EDS maps and spectra were collected using the FEI Super-X EDS setup with four EDS detectors, thereby increasing the signal counts. Before STEM-EDS mapping, the sapphire substrate was tilted in the $[2 \overline{1} \overline{10}]$ zone axis, so as to make the electron beam parallel to the substrate/film interface and perpendicular to the film growth direction, the c axis of the sapphire substrate. The maps and spectra were analyzed using the Bruker Esprit 1.9 software. The absolute error in the quantification was determined to be below 4.70 at. \%. For an in-depth STEM study of the samples, see the recent publication by Zhan et al. ${ }^{23}$

The resistivity and charge carrier density were measured at room temperature with a LakeShore 7704A Hall Measurement System using a Van der Pauw configuration. Sample thicknesses were estimated from STEM images.

\section{RESULTS AND DISCUSSION}

Figure 3 shows the results from the STEM-EDS investigation of the samples. In order to accurately quantify the vertical grading, the compositions were averaged over areas of $109 \mathrm{~nm} \times 3 \mathrm{~nm}\left(\mathrm{Cd}_{05}\right), 53 \mathrm{~nm} \times 4 \mathrm{~nm}\left(\mathrm{Cd}_{09}\right), 408 \mathrm{~nm} \times 3 \mathrm{~nm}$ $\left(\mathrm{Cd}_{13}\right)$, and $440 \mathrm{~nm} \times 3 \mathrm{~nm}\left(\mathrm{Cd}_{16}\right)$ to produce the line profiles in Fig. 3(a). As an illustration, Figs. 3(b) and 3(c) show the EDS mapping of $\mathrm{Cd}$ and $\mathrm{Zn}$, respectively, from sample $\mathrm{Cd}_{13}$. The Cd containing film is clearly distinguishable from the $\mathrm{ZnO}$ buffer layer. Both layers are typically about $100-120 \mathrm{~nm}$ thick. All samples reveal statistically significant variations in the $\mathrm{Cd}$ content. For the samples $\mathrm{Cd}_{05}, \mathrm{Cd}_{09}$, and $\mathrm{Cd}_{16}$, the $\mathrm{Cd}$ content is the highest closest to the pure $\mathrm{ZnO}$ interface and decreases in a nearly linear manner towards the sample surface. For sample $\mathrm{Cd}_{13}$, the $\mathrm{Cd}$ content is the highest in the middle of the $\mathrm{Zn}_{1-x} \mathrm{Cd}_{x} \mathrm{O}$ film, after which it drops off again towards the sample surface. The data are listed in Table I. Quantitative XPS analysis was used to determine the surface composition of the samples after gentle $\mathrm{Ar}^{+}$sputter removal of the carbon contamination layer. At the surface, $\mathrm{Cd}_{05}, \mathrm{Cd}_{09}, \mathrm{Cd}_{13}$, and $\mathrm{Cd}_{16}$ were found to have $x=0.01$, $0.03,0.05$, and 0.08 , respectively. This is generally somewhat lower than the compositions measured by STEM-EDS in Fig. 3. This can be due to the fact that the STEM-EDS investigation does not provide the true composition at the outermost surface, e.g., because of surface roughness. Some 


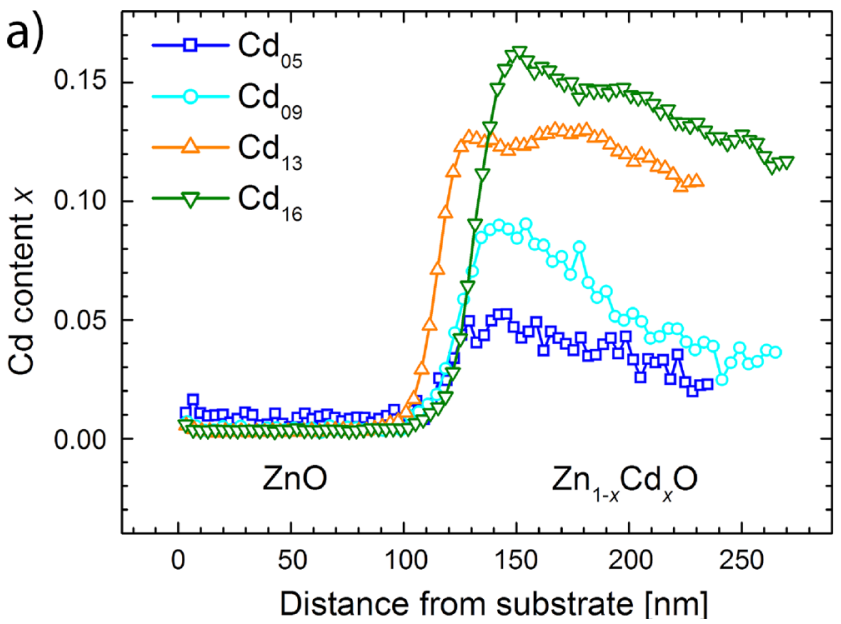

preferential sputtering may also occur although the sputter yields of $\mathrm{Zn}$ and $\mathrm{Cd}$ are not severely different. ${ }^{24}$

Figure 4 shows CL spectra from the samples studied by STEM-EDS. A clear shift in the NBE peak position is seen as a function of the electron beam energy. In general, the bandgap decreases with increasing electron beam energy, i.e., deeper penetration depth, consistent with the variation in the Cd content found from STEM-EDS. For each sample, the spectrum acquired at the lowest beam energy was peak fitted in order to extract bandgap values from the sample depth corresponding to the XPS measurement. The fitting strategy for such samples is not unambiguous: As shown in Fig. 2(b), the NBE peak contains several phonon replicas, resulting in an asymmetric overall peak shape with the true NBE position shifted to slightly higher energies than the apparent peak maximum. The width, separation, and relative intensity of the replicas depend on the material and are not known for the $\mathrm{Zn}_{1-x} \mathrm{Cd}_{x} \mathrm{O}$ system. Furthermore, the compositional inhomogeneity of the samples means that the CL spectrum will consist of several overlapping NBE peaks from different sample regions exhibiting different bandgaps. For the present purpose, we chose a simplified fitting procedure focusing on comparability between the different samples: The spectra were fitted with one main NBE peak, consisting of replica peaks with separation and relative intensity taken from pure $\mathrm{ZnO}$. The full-width-at-half-maximum (FWHM), however, was allowed to increase compared to pure $\mathrm{ZnO}$ in order to represent the spread in bandgap values within the measurement volume. A limited number of generic peaks were added

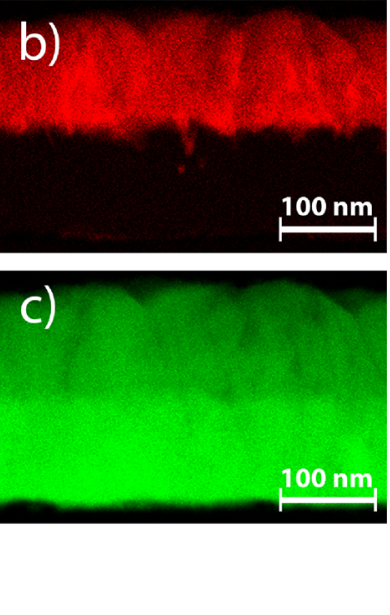

FIG. 3. STEM-EDS investigation of the sample composition: (a) Cd content $(x)$ as a function of the distance from the substrate/film interface. (b) $\mathrm{Cd}$ EDS map and (c) Zn EDS map from the $\mathrm{Cd}_{13}$ sample. to the lower energy region to represent unknown/unresolved defect peaks. This was done in order to avoid unphysical behavior of the NBE peaks, as detailed analysis of the defects in the $\mathrm{Zn}_{1-x} \mathrm{Cd}_{x} \mathrm{O}$ system was beyond the scope of this work. For $\mathrm{Cd}_{05}$ and $\mathrm{Cd}_{09}$, the NBE peak of pure $\mathrm{ZnO}$ was added to the higher energy side. More elaborate peak fitting schemes were explored but not found to offer increased accuracy due to the large number of unknown variables. The fitted CL spectra are shown in Fig. 5, and the extracted bandgap values are listed in Table I.

Detailed XPS measurements of the valence region were conducted in order to find the position of $\mathrm{E}_{\mathrm{V}}$ as a function of the $\mathrm{Cd}$ content. A nearly linear shift in $\mathrm{E}_{\mathrm{V}}$ as a function of $x$ is seen in Fig. 6(a). An important thing to remember at this point, however, is that XPS measures energies relative to $\mathrm{E}_{\mathrm{F}}$. Thus, if the $\mathrm{E}_{\mathrm{F}}$ position shifts within the bandgap, i.e., if the workfunction of the material changes, the entire XPS spectrum will shift accordingly. The work function can be affected by changes in two independent quantities: (1) The distance between $\mathrm{E}_{\mathrm{F}}$ and the band edges and (2) the distance between the vacuum level ( $\left.\mathrm{E}_{\mathrm{vacuum}}\right)$ and the band edges, i.e., the ionization potential $\left(\mathrm{I}_{\mathrm{P}}\right)$ or the electron affinity $(\chi){ }^{25}$ Changes in the $\mathrm{E}_{\mathrm{F}}$ position can be seen as a result of doping or surface band bending. In the case of $\mathrm{Zn}_{1-x} \mathrm{Cd}_{x} \mathrm{O}$, there is also a change in the magnitude of the bandgap, which may affect the position of the Fermi level in unknown ways. These aspects complicate the comparison of absolute $\mathrm{E}_{\mathrm{V}}$ positions between the samples. After analyzing the core spectra, however, it was found that the distances between $E_{V}$

TABLE I. Sample details for $\mathrm{Zn}_{1-x} \mathrm{Cd}_{x} \mathrm{O}$.

\begin{tabular}{|c|c|c|c|c|c|}
\hline $\begin{array}{l}\text { Sample } \\
\text { name }\end{array}$ & $\begin{array}{l}\text { Maximum Cd } \\
\text { content }^{\mathrm{a}} x\end{array}$ & $\begin{array}{c}\text { Surface } \\
\text { composition }^{\mathrm{b}} x\end{array}$ & $\begin{array}{c}\mathrm{E}_{\mathrm{V}} \text { position relative } \\
\text { to } \mathrm{E}_{\mathrm{F}}(\mathrm{eV})\end{array}$ & $\begin{array}{l}\text { Auger parameter } \\
\text { Zn 2p-LMM (eV) }\end{array}$ & $\begin{array}{c}\text { Surface bandgap }{ }^{c} \\
E_{g}(e V)\end{array}$ \\
\hline $\mathrm{ZnO}$ & 0.00 & 0.00 & $3.24(5)$ & $2010.08(14)$ & 3.31 \\
\hline $\mathrm{Cd}_{05}$ & 0.05 & 0.01 & $3.24(5)$ & $2010.16(14)$ & 3.30 \\
\hline $\mathrm{Cd}_{09}$ & 0.09 & 0.03 & $3.14(5)$ & $2010.12(14)$ & 3.03 \\
\hline $\mathrm{Cd}_{13}$ & 0.13 & 0.05 & $3.05(5)$ & $2010.15(14)$ & 2.94 \\
\hline $\mathrm{Cd}_{16}$ & 0.16 & 0.08 & $2.88(5)$ & $2010.13(14)$ & 2.80 \\
\hline
\end{tabular}

${ }^{\mathrm{a}}$ Measured by STEM-EDS.

${ }^{\mathrm{b}}$ Measured by XPS.

${ }^{\mathrm{c}}$ Measured by CL. 

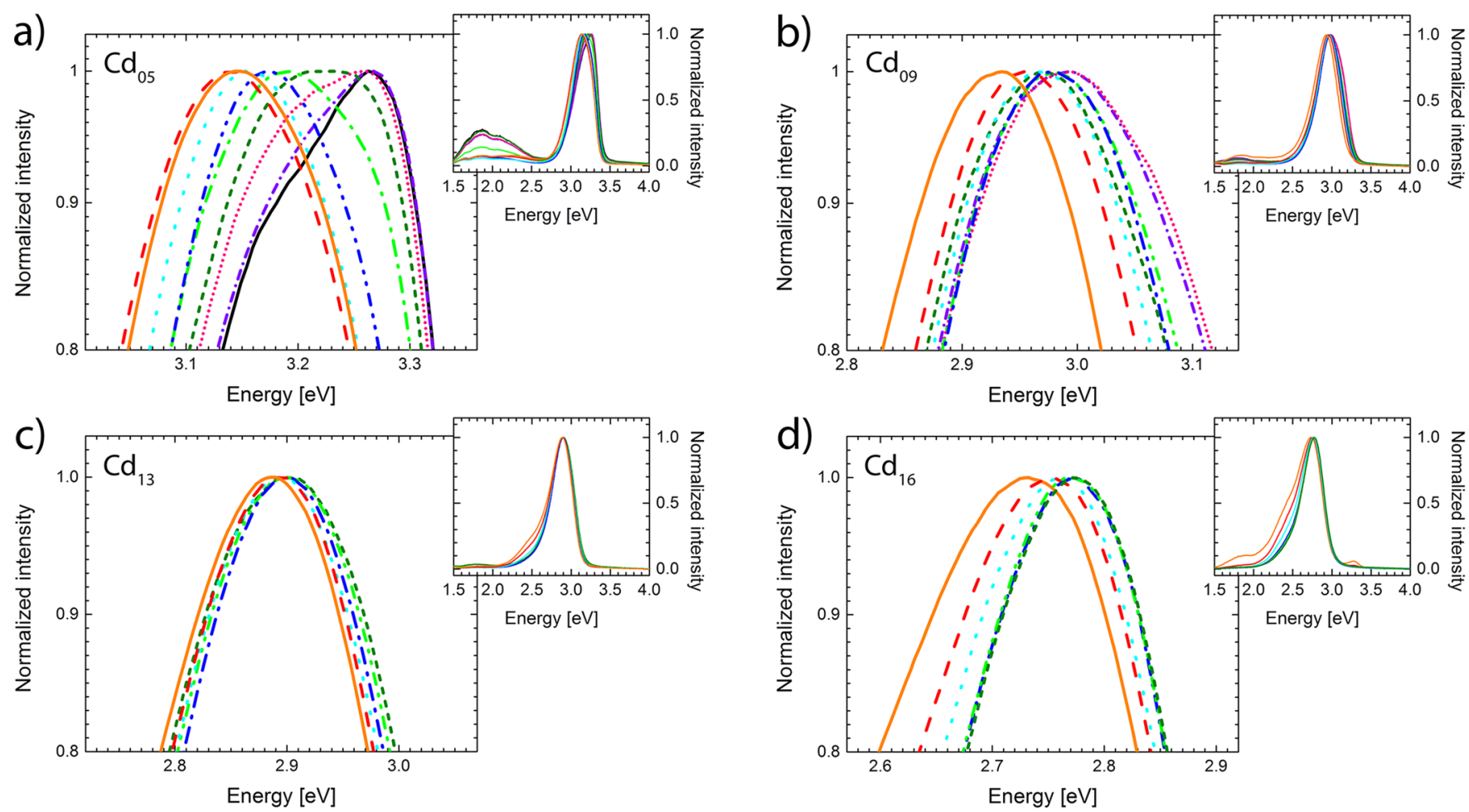

Beam energy: $\longrightarrow 0.2 \mathrm{kV}-\cdot-0.3 \mathrm{kV} \cdots \cdots \cdot 0.4 \mathrm{kV}---0.5 \mathrm{kV}--1.0 \mathrm{kV} \quad-\cdots 2.0 \mathrm{kV}=-3.0 \mathrm{kV} \quad-\quad-4.0 \mathrm{kV} \quad-5.0 \mathrm{kV}$

FIG. 4. CL spectra from samples $\mathrm{Cd}_{05}$ (a), $\mathrm{Cd}_{09}$ (b), $\mathrm{Cd}_{13}$ (c), and $\mathrm{Cd}_{16}$ (d). The region around the NBE peak maximum is enhanced, while the full spectra are included as insets. In general, a decrease in the bandgap is observed with increasing electron beam energy, i.e., the increasing sample depth, in agreement with the gradient in the Cd content.

and the $\mathrm{Zn} 2 \mathrm{p}, \mathrm{Cd} 3 \mathrm{~d}$, and $\mathrm{O} 1 \mathrm{~s}$ core level peaks were constant in all the samples, within the accuracy of the measurements [see Fig. 6(b)]. The Zn 2p-LMM Auger parameter ${ }^{26}$ (AP) was also found to be constant (see Table I). It is highly unlikely that the introduction of $\mathrm{Cd}$ would cause both the valence levels and the core levels to shift by exactly the same amount. Sample charging, which is another possible source of uniform peak shifts, was already tested and ruled out. Thus, if we interpret the constant $\mathrm{E}_{\mathrm{V}}$-to-core level distances and APs as a sign that $\mathrm{Cd}$ does not cause changes in a)
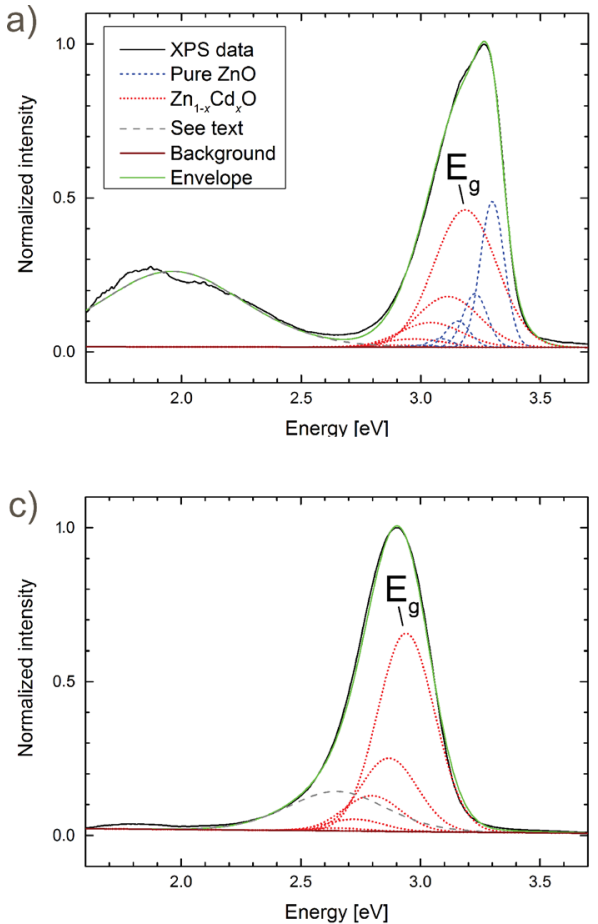

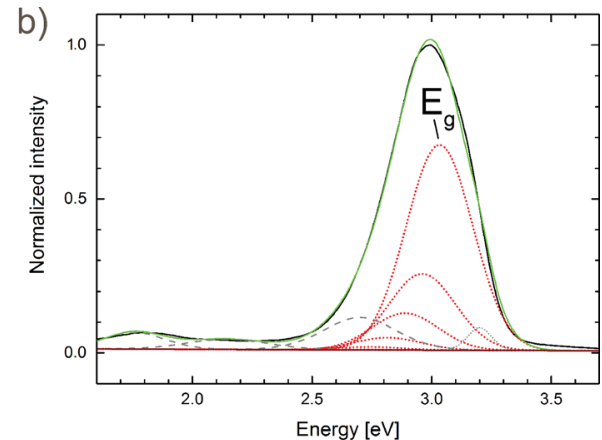

d)

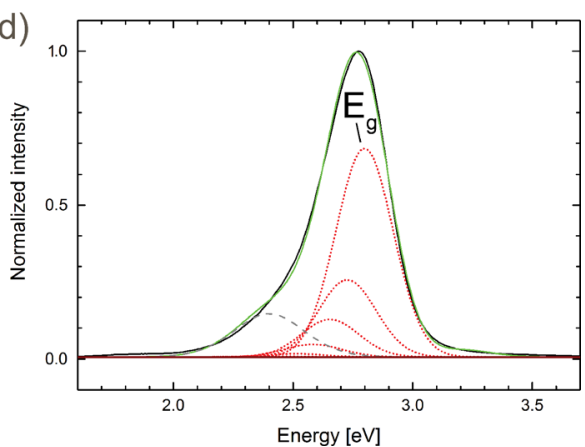

FIG. 5. CL spectra (black solid) from the outermost surface (the lowest electron beam energy) of samples $\mathrm{Cd}_{05}$ (a), $\mathrm{Cd}_{09}$ (b), $\mathrm{Cd}_{13}$ (c), and $\mathrm{Cd}_{16}$ (d). The NBE peaks of $\mathrm{Zn}_{1-x} \mathrm{Cd}_{x} \mathrm{O}$ (red dot) and pure $\mathrm{ZnO}$ (blue short dash) are fitted with a series of phonon replicas. The position of the first peak gives the bandgaps $\left(\mathrm{E}_{\mathrm{g}}\right)$ listed in Table I. A limited number of generic peaks (grey dash) were added in order to represent unknown/unresolved defects on the lower energy side. 
a)
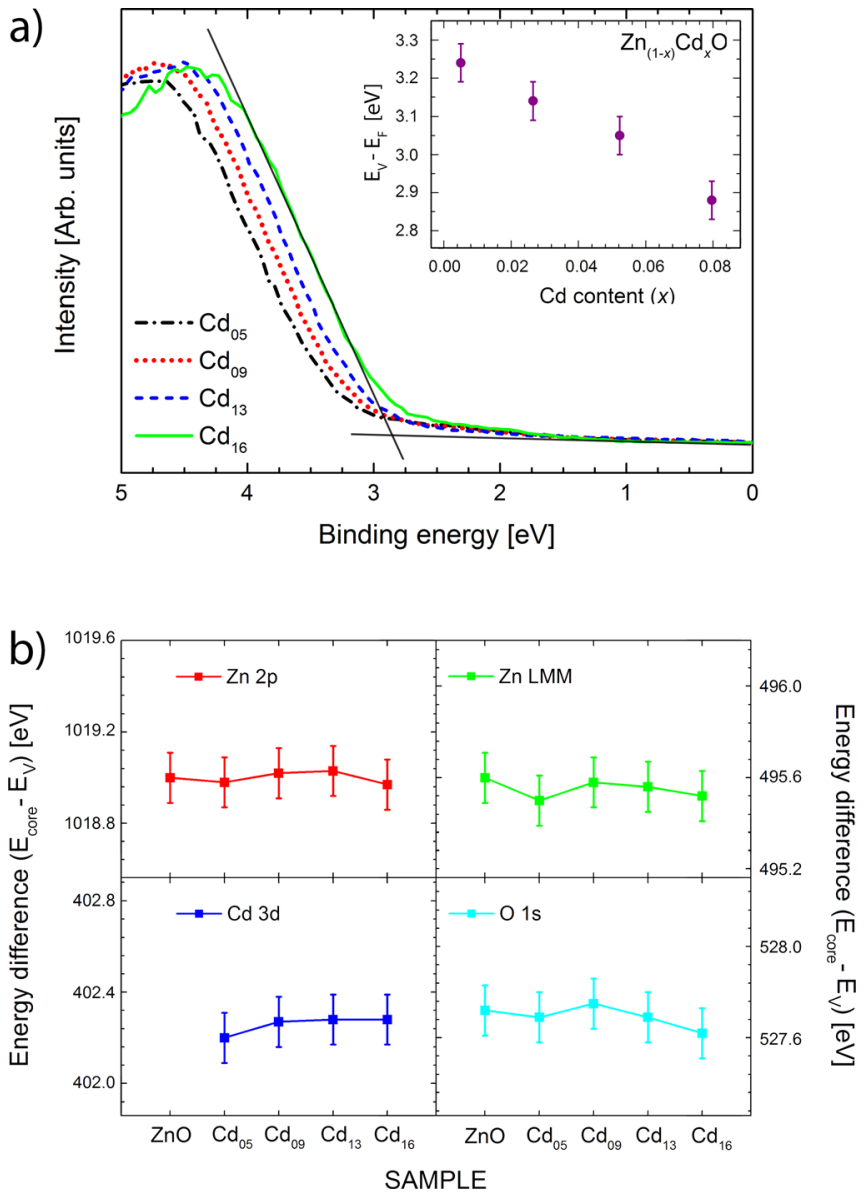

FIG. 6. XPS results: (a) valence spectra from samples $\mathrm{Cd}_{05}$ (black dash-dot), $\mathrm{Cd}_{09}$ (red dot), $\mathrm{Cd}_{13}$ (blue dash), and $\mathrm{Cd}_{16}$ (green solid). The black intersecting lines are included to illustrate the method for $\mathrm{E}_{\mathrm{V}}$ determination. The inset shows the distance between $\mathrm{E}_{\mathrm{V}}$ and $\mathrm{E}_{\mathrm{f}}$ with standard deviations, as measured from the XPS valence spectra. (b) The energy difference between $E_{V}$ and relevant core level peaks with standard deviations, as measured by XPS.

the valence and core levels, i.e., $\mathrm{I}_{\mathrm{P}}$ remains constant for the increasing $\mathrm{Cd}$ content, the relative bandstructure of the $\mathrm{Zn}_{1-x} \mathrm{Cd}_{x} \mathrm{O}$ samples can be established using the core levels for the alignment. In Fig. 7, $\mathrm{E}_{\mathrm{V}}$ and core levels are aligned,
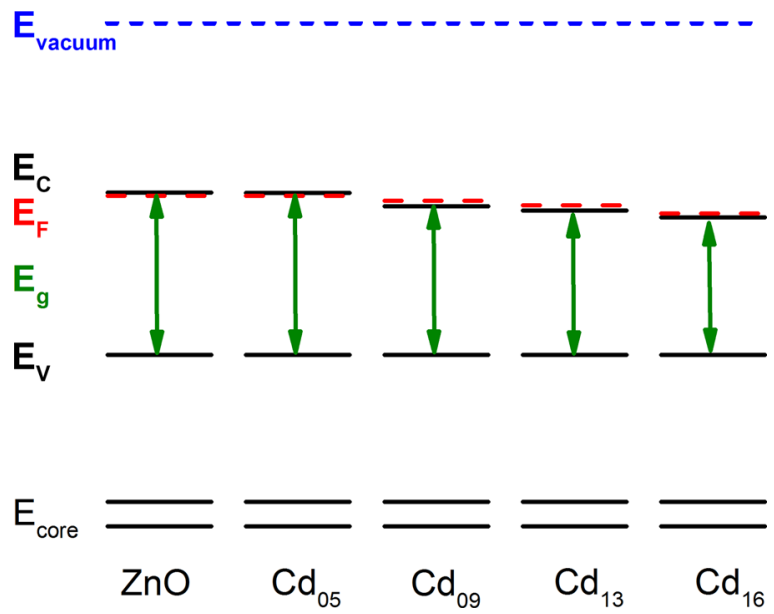

FIG. 7. Schematic illustrations of the band structure near the surface of the $\mathrm{Zn}_{1-x} \mathrm{Cd}_{x} \mathrm{O}$ samples after alignment of the occupied levels. $\mathrm{E}_{\mathrm{V}}$ and $\mathrm{E}_{\mathrm{F}}$ positions from XPS are combined with $\mathrm{E}_{\mathrm{g}}$ from $\mathrm{CL}$ to determine $\mathrm{E}_{\mathrm{C}}$. while the distance between $\mathrm{E}_{\mathrm{F}}$ and $\mathrm{E}_{\mathrm{vacuum}}$ is seen to increase with the increasing $\mathrm{Cd}$ content. The $\mathrm{E}_{\mathrm{C}}$ position is found using the bandgap values as measured by low electron energy CL. Two things are worth noting from Fig. 7: (i) For the present samples, the change in $\mathrm{E}_{\mathrm{g}}$ due to $\mathrm{Cd}$ appears to be accommodated primarily by changes in the conduction band. (ii) For all samples except $\mathrm{Cd}_{05}, \mathrm{E}_{\mathrm{F}}$ appears to lie above $\mathrm{E}_{\mathrm{C}}$. Additional work is needed to clarify whether the latter is a bulk material property or just a surface bandbending effect observed by XPS.

In Fig. 8(a), the results of Hall measurements show an increased carrier concentration as a function of the increasing $\mathrm{Cd}$ content. For pure $\mathrm{ZnO}$, the growth conditions are slightly oxygen-rich, but with an increased DMCd-flow, the growth conditions shift towards oxygen-poor/metal rich since the flow rate of $\mathrm{t}-\mathrm{BuOH}$ is kept constant for all samples, explaining this general trend of the increasing carrier concentration. However, for the highest $\mathrm{Cd}$ content $\left(\mathrm{Cd}_{16}\right.$ sample), the carrier concentration is again reduced as compared to the $\mathrm{Cd}_{13}$ sample. Interestingly, the mobility is at the same time increased (not shown), which is consistent with a higher incorporation of $\mathrm{Cd}$ on the $\mathrm{Zn}$-site combined with a lower Cd-interstitial donor concentration in the film. ${ }^{27} \mathrm{At}$ low DMCd flow rates, the incorporation efficiency of $\mathrm{Cd}$ into $\mathrm{ZnO}$ is low and $\mathrm{Zn} / \mathrm{Cd}$-rich conditions introduce $\mathrm{Zn}_{\mathrm{i}}$ (or $\mathrm{Cd}_{\mathrm{i}}$ ), which acts as a donor. However, at a high DMCd flow rate, the $\mathrm{Cd}$ incorporation efficiency increases, in turn
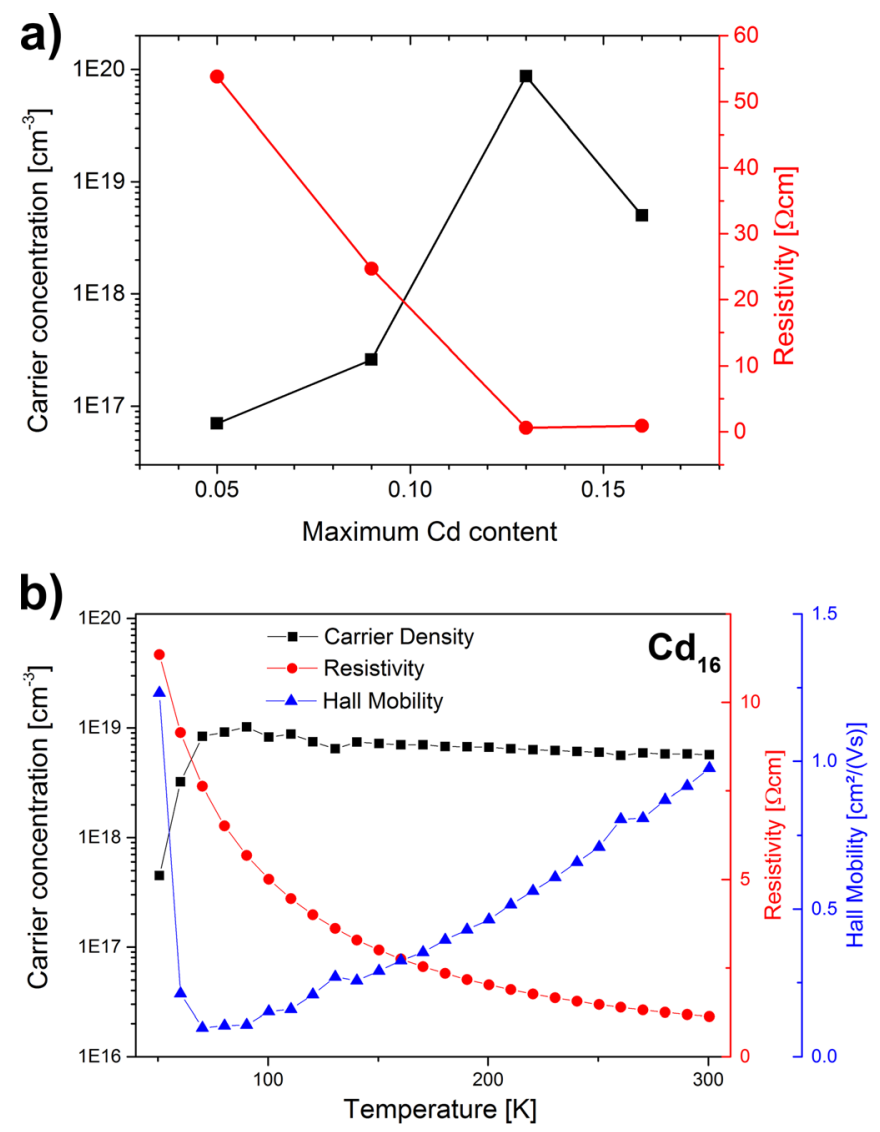

FIG. 8. Hall measurements as a function of (a) the maximum Cd content (all samples) and (b) temperature (sample $\mathrm{Cd}_{16}$ as an example): carrier concentration (squares), resistivity (circles), and Hall mobility (triangles). 


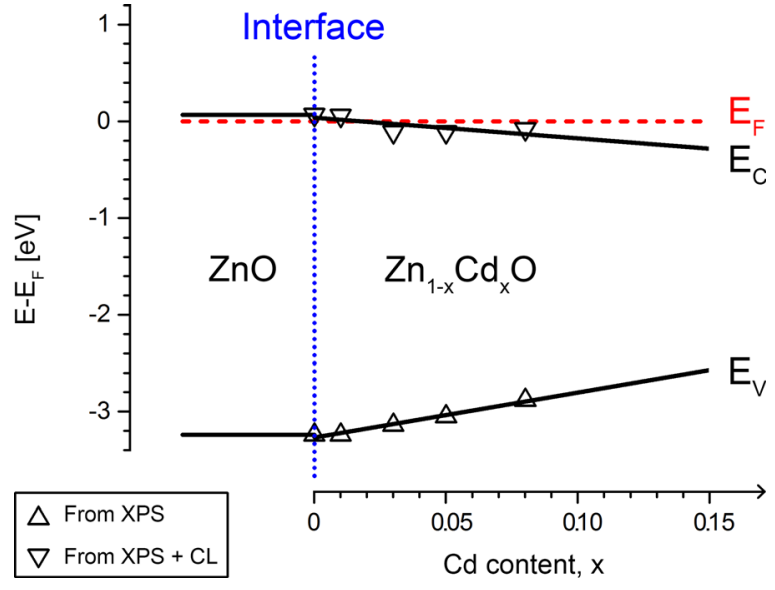

FIG. 9. Schematic illustrations of the possible band structure for compositionally graded $\mathrm{Zn}_{1-x} \mathrm{Cd}_{x} \mathrm{O}$ on a pure $\mathrm{ZnO}$ substrate, extrapolated from XPS and CL measurements.

influencing the formation of interstitial defects. A similar trend was observed by Kumar et al. in samples synthesized by reactive dc magnetron sputtering. ${ }^{28}$

In the work of Makino and Segawa Ga-doped, $\mathrm{ZnO}$ was found to have $\mathrm{E}_{\mathrm{F}}>\mathrm{E}_{\mathrm{C}}$ at $300 \mathrm{~K}$ for carrier concentrations exceeding $10^{19}-10^{20} \mathrm{~cm}^{-3} \cdot{ }^{29}$ This indicates that the carrier concentrations measured for the present $\mathrm{Zn}_{1-x} \mathrm{Cd}_{x} \mathrm{O}$ samples are in the correct order of magnitude to exhibit degenerate behavior. However, the extraction of values for the carrier concentration from Hall measurements does not take into account the compositional grading. Figure 8(b) show temperature dependent Hall measurements for the $\mathrm{Cd}_{16}$ sample. These measurements suggest the semiconductor behavior, as the resistivity decreases with increasing temperature. Alternatively, the $E_{F}>E_{C}$ behavior may also be an effect of surface bandbending: Previously, a strong downward surface bandbending effect has been reported for pure $\mathrm{ZnO}{ }^{30}$ Furthermore, extreme downward bandbending and $\mathrm{E}_{\mathrm{F}}>\mathrm{E}_{\mathrm{C}}$ were also observed for rocksalt-phase $n$-type $\mathrm{CdO}$, caused by an accumulation of electrons forming quantized electron subband states near the surface. ${ }^{31}$ Thus, a similar effect could be present for $\mathrm{Zn}_{1-x} \mathrm{Cd}_{x} \mathrm{O}$ as well.

The bandstructure data discussed so far were extracted from the near-surface area of different samples. In the following paragraph, we combine the surface data from these samples to predict the band structure evolution along the growth direction of a compositionally graded $\mathrm{Zn}_{1-x} \mathrm{Cd}_{x} \mathrm{O}$ film. The position of $\mathrm{E}_{\mathrm{V}}$ relative to $\mathrm{E}_{\mathrm{F}}$ was obtained from the XPS data, while $E_{V}$ could be combined with $E_{g}$ found by $\mathrm{CL}$, to determine the position of $\mathrm{E}_{\mathrm{C}}$. The obtained $\mathrm{E}_{\mathrm{V}}$ and $\mathrm{E}_{\mathrm{C}}$ values were plotted as a function of the $\mathrm{Cd}$ content and fitted with linear functions. These graphs were in turn incorporated into a schematic illustration of the graded $\mathrm{ZnCdO}$ (n-type) side of a possible PID-junction, as presented in Fig. 9. It is important to note that the change in the position of $\mathrm{E}_{\mathrm{V}}$ relative to $\mathrm{E}_{\mathrm{F}}$ in this representation of the data is not an indication of changes in the valence band. In Fig. 9, the Fermi levels are aligned, which is what happens upon electrical contact. This gives the impression that the valence band changes but is in reality an effect of bandbending, where the compositionally graded film behaves similar to a heterostructure made of very thin layers.

\section{CONCLUSIONS}

The bandgap and band edge positions of compositionally graded $\mathrm{Zn}_{1-x} \mathrm{Cd}_{x} \mathrm{O}$ samples made by MOVPE were investigated using a combination of XPS and CL. Common pitfalls related to XPS energy referencing were resolved. First, it was shown how sample charging during XPS measurements can be minimized by depositing proper metal contacts onto the $\mathrm{Zn}_{1-x} \mathrm{Cd}_{x} \mathrm{O}$ samples. Second, it was emphasized how changes in the Fermi level position relative to vacuum, i.e., the workfunction, complicate the comparison of XPS data from different samples. Taking the latter into account, it was found that introducing $\mathrm{Cd}$ into $\mathrm{ZnO}$ does not significantly alter the band structure below the Fermi level. Hence, the reduction of the bandgap upon alloying with $\mathrm{Cd}$ must be accommodated primarily by changes in the conduction band. Bandgap values were obtained from low energy CL and combined with the XPS data to sketch the band structure of graded $\mathrm{Zn}_{1-x} \mathrm{Cd}_{x} \mathrm{O}$ heterostructures.

\section{ACKNOWLEDGMENTS}

L.J.B. acknowledges the support from National Science Foundation under Grant No. DMR-1305193. K.M.J. would like to thank the Norwegian Research Council for the support to the DYNAZOx Project (221992). A.Yu.K. and V.V. would like to thank the Norwegian Research Council for the support to the MIDAS (228578) and P2V (255082) Projects. W.Z. and Ø.P. are grateful to the Norwegian Research Council for supporting the Norwegian Center for Transmission Electron Microscopy, NORTEM (197405/ F50).

${ }^{1}$ P. F. Carcia, R. S. McLean, M. H. Reilly, and G. Nunes, Jr., Appl. Phys. Lett. 82, 1117 (2003).

${ }^{2}$ E. M. C. Fortunato, P. M. C. Barquinha, A. C. M. B. G. Pimentel, A. M. F. Goncalves, A. J. S. Marques, L. M. N. Pereira, and R. F. P. Martins, Adv. Mater. 17, 590 (2005).

${ }^{3}$ X. Du, Z. Mei, Z. Liu, Y. Guo, T. Zhang, Y. Hou, Z. Zhang, Q. Xue, and A. Y. Kuznetsov, Adv. Mater. 21, 4625 (2009).

${ }^{4}$ M. Trunk, A. Gorzkowska-Sobas, V. Venkatachalapathy, T. Zhang, A. Galeckas, and A. Y. Kuznetsov, Energy Procedia 22, 101 (2012).

${ }^{5}$ D. Ielmini, Semicond. Sci. Technol. 31, 063002 (2016).

${ }^{6}$ W. Walukiewicz, D. Detert, K. M. Yu, and M. Ristova, "CdZnO/Si tandem cell for photoelectrochemical water dissociation," U.S. patent 20170076875 (Sept. 9, 2015)

${ }^{7}$ A. A. Metri, T. S. Rani, and P. Sharan, in Silicon Photonics and High Performance Computing. Advances in Intelligent Systems and Computing, edited by A. Mishra, A. Basu, and V. Tyagi (Springer, Singapore, 2018), Vol. 718.

${ }^{8}$ L. Vines and A. Y. Kuznetsov, in Oxide Semiconductors, edited by B. G. Svensson, S. J. Pearton, and C. Jagadish (Academic Press, 2013), Vol. 88, pp. 67-104.

${ }^{9}$ D. Jena, S. Heikman, D. Green, D. Buttari, R. Coffie, H. L. Xing, S. Keller, S. Denbaars, J. S. Speck, U. K. Mishra et al., Appl. Phys. Lett. 81, 4395 (2002).

${ }^{10}$ J. Simon, V. Protasenko, C. Lian, H. Xing, and D. Jena, Science 327, 60 (2010).

${ }^{11}$ J. J. Ibbetson, P. Fini, K. Ness, S. DenBaars, J. Speck, and U. Mishra, Appl. Phys. Lett. 77, 250 (2000).

${ }^{12}$ A. Franciosi and C. G. Van de Walle, Surf. Sci. Rep. 25, 1 (1996).

${ }^{13}$ A. Klein, Thin Solid Films 520, 3721 (2012). 
${ }^{14}$ R. T. Tung, Appl. Phys. Rev. 1, 011304 (2014).

${ }^{15}$ X. D. Zhang, M. L. Guo, W. X. Li, and C. L. Liu, J. Appl. Phys. 103, 063721 (2008).

${ }^{16}$ J. J. Chen, F. Ren, Y. Li, D. P. Norton, S. J. Pearton, A. Osinsky, J. W. Dong, P. P. Chow, and J. F. Weaver, Appl. Phys. Lett. 87, 192106 (2005).

${ }^{17}$ H. H.-C. Lai, V. L. Kuznetsov, R. G. Egdell, and P. P. Edwards, Appl. Phys. Lett. 100, 072106 (2012).

${ }^{18}$ D. M. Detert, K. B. Tom, C. Battaglia, J. D. Denlinger, S. H. N. Lim, A. Javey, A. Anders, O. D. Dubon, K. M. Yu, and W. Walukiewicz, J. Appl. Phys. 115, 233708 (2014).

${ }^{19}$ D. A. Shirley, Phys. Rev. B 5, 4709 (1972).

${ }^{20}$ See http://www.casaxps.com for information about the CasaXPS software, 2012.

${ }^{21}$ D. Drouin, Microsc. Microanal. 12, 1512 (2006).

${ }^{22}$ W. Shan, W. Walukiewicz, J. W. Ager, K. M. Yu, H. B. Yuan, H. P. Xin, G. Cantwell, and J. J. Song, Appl. Phys. Lett. 86, 191911 (2005).
${ }^{23}$ W. Zhan, C. Granerød, V. Venkatachalapathy, K. M. Johansen, I. J. T. Jensen, A. Y. Kuznetsov, and Prytz, Nanotechnology 28, 10 (2017).

${ }^{24}$ National Physical Laboratory, http://www.npl.co.uk/science-technology/ surface-and-nanoanalysis/services/sputter-yield-values for sputter yield values, 2016.

${ }^{25}$ A. Klein, J. Am. Ceram. Soc. 96, 331 (2013).

${ }^{26}$ G. Moretti, J. Electron Spectrosc. Relat. Phenom. 95, 95 (1998).

${ }^{27}$ V. Venkachalapathy, A. Galeckas, M. Trunk, T. Zhang, A. Azarov, and A. Y. Kuznetsov, Phys. Rev. B 83, 125315 (2011).

${ }^{28}$ A. G. S. Kumar, L. Obulapathi, T. S. Sarmash, D. J. Rani, M. Maddaia, T. S. Rao, and K. Asokan, JOM 67, 834 (2015).

${ }^{29}$ T. Makino and Y. Segawa, Appl. Phys. Lett. 85, 759 (2004).

${ }^{30}$ M. W. Allen, C. H. Swartz, T. H. Myers, T. D. Veal, C. F. McConville, and M. Durbin, Phys. Rev. B 81, 075211 (2010).

${ }^{31}$ L. F. J. Piper, L. Colakerol, P. D. C. King, A. Schleife, J. Zúniga-Pérez, P. A. Glans, T. Leramoth, A. Federov, T. D. Veal, F. Fuchs, V. MunozSanjosé et al., Phys. Rev. B 78, 165127 (2008). 